\title{
Can we offer more for cognitive impairment in patients with chronic hepatitis $\mathrm{C}$ ?
}

\author{
É possivel oferecer algo a mais para pacientes com hepatite $\mathrm{C}$ crônica com \\ comprometimento cognitivo?
}

Ugo NOCENTINI ${ }^{1,2}$

Chronic hepatitis $\mathrm{C}(\mathrm{CHC})$ represents a significant personal and public health burden: worldwide, 1,750,000 new infections and 400,000 deaths from CHC and its consequences $^{1}$ occurred in 2015. The prevalence estimate, on a global scale, is about 200 million people affected.

Involvement in patients with $\mathrm{CHC}$ presents with a broad spectrum of signs and symptoms ${ }^{2,3,4}$. Among the possible consequences of central nervous system (CNS) damage, neuropsychiatric disorders are of pivotal importance not only because of their intrinsic relevance, but also because they can easily be missed.

Among the cognitive dysfunctions, concentration difficulties and slowed thinking stand out, but other functions can be compromised as well (calculation, sustained attention, information processing speed, memory and learning). On the psychiatric side, depression is in the foreground, but other disorders are also frequent ${ }^{2,3,4}$.

Similar to what occurs in other CNS diseases, the reactive component and primary biological aetiology of depression are not easy to distinguish ${ }^{4}$. The feeling of pathological fatigue is also very common ${ }^{4}$.

About the pathogenesis of cognitive disorders, there are $\mathrm{EEG}^{3}$, structural and functional MRI data, PET and SPECT ${ }^{2,3,4}$ data highlighting dysfunctions and damage to the frontal white matter, the cortical and subcortical grey matter (e.g., basal ganglia). It has to be noted that several of these data suggest the presence of inflammatory phenomena.

Based on numerous data, the aforementioned cognitive disorders are to be considered an extrahepatic manifestation of CHC. It is still not clear whether brain damage is the consequence of viral presence in the CNS or the result of extraand intra-cerebral immune activation: in $\mathrm{CHC}$, the activation of immune mechanisms occurs at both systemic level and cerebral level, regardless of the presence of the virus ${ }^{3}$.
The link between active inflammatory processes within the CNS and cognitive dysfunction has been demonstrated in HIV encephalopathy, multiple sclerosis (MS) and in more properly degenerative diseases, such as Alzheimer's disease (AD). In MS, dysfunctions resulting from inflammation are also linked to direct action on the synaptic function of inflammation mediators 5 .

In $\mathrm{AD}$ the role of inflammatory processes, not secondary to other pathophysiological events but possible primary events, has been highlighted: the precise role of innate and adaptive immunity in typical neuro-inflammatory diseases (e.g., MS) compared to $\mathrm{AD}$ is not clear yet ${ }^{6,7}$.

Given the prevalence and serious consequences of $\mathrm{CHC}$, the identification of therapies able to reduce the presence of the virus in the body has been intensely pursued.

The first therapy with significant efficacy, based on Interferon $\alpha$, is burdened by not negligible side effects, precisely on psychiatric and cognitive functions ${ }^{3,8}$ even if other possible causes for those symptoms cannot be overlooked ${ }^{9}$. The advent of direct-acting antiviral (DAA) has been significantly appreciated.

The work of Gascon et al. ${ }^{10}$ re-proposes the issue of cognitive impairment in patients with $\mathrm{CHC}$ and, notably, examines the benefits of DAAs on cognitive functioning: the effects of therapy with three DAAs on cognitive functioning and depression levels severity in a sample of 58 patients with $\mathrm{CHC}$ has been examined through three evaluations: before, immediately after and six months after treatment. Cognitive assessment was based on a large series of neuropsychological tests; depression and other aspects were also evaluated with standardized tools. The sample was composed of subjects with HCV genotype 1 infection, without significant liver damage and without serious comorbidities; despite this, at the initial assessment, more than $70 \%$ had some degree of cognitive

\footnotetext{
"Università di Roma “Tor Vergata”, Dipartimento di Scienze Cliniche e Medicina Traslazionale, Roma, Italia.

${ }^{2}$ Fondazione "Santa Lucia" Istituto di Ricovero e Cura a Carattere Scientifico, Roma, Italia.

Ugo NOCENTINI (iD https://orcid.org/0000-0001-7445-4441

Correspondence: Ugo Nocentini; E-mail:u.nocentini@hsantalucia.it

Conflict of interest: There is no conflict of interest to declare.

Received on May 19, 2020; Received in its final form on May 19, 2020; Accepted on May 21, 2020.
} 
impairment; at the six-month evaluation, subjects with preserved cognitive functions went from 27.5 to $50 \%$; the cognitive domains in which a significant improvement was found were episodic verbal memory and visuo-spatial memory. There was no significant improvement in depression levels. Drug therapy has focused on sofosbuvir in various combinations with simeprevir, daclatasvir and ribavirin.

This relevant study suggests several reflections. Cognitive disorders are quite common in patients with $\mathrm{CHC}$ even without significant liver damage: therefore, the aetiology of these disorders must be sought in direct brain damage.

DAA therapy allows the recovery of normal cognitive function without leading to significant negative effects on other functional aspects (e.g., mood). Cognitive performance improvement is not directly linked to depression improvement.

According to data from the study by Gascon et al. ${ }^{10}$, cognitive impairment and its variations are not influenced by premorbid intellectual capacity (cognitive reserve). The cognitive reserve, however, is a complex construct ${ }^{11}$ that deserves a thorough evaluation.
The positive effects of DAA therapy on cognitive functioning are likely to be more significant when treatment is instituted before cognitive impairment involves multiple domains. This opens the discussion on the usefulness of an early cognitive screening in all patients with HCV infection.

Other interesting perspectives are indicated by the work of Gascon et al. ${ }^{10}$ : Are there any predisposing or protective factors towards the possible cognitive impairment in patients with $\mathrm{CHC}$ (e.g., ApoE genotype) that are worth exploring? It would be interesting to follow $\mathrm{CHC}$ patients longitudinally, distinguishing responders from non-responders to DAAs, to assess the incidence of forms of dementia or other degenerative or inflammatory CNS diseases. An in-depth investigation on the pathogenesis of cognitive disorders with further studies of neuroimaging and neuro-transmitter variations also appear fundamental. Equally important is to evaluate the correlations between cognitive disorders, fatigue, resilience and psycho-emotional factors.

As always, a study, even well designed, provides not only some answers, but also, perhaps more, new questions.

\section{References}

1. Thomas DL. Global elimination of chronic hepatitis. N Engl J Med. 2019 May;380(21):2041-50. https://doi.org/10.1056/nejmra1810477

2. Mathew S, Faheem M, Ibrahim SM, Iqbal W, Rauff B, Kaneez F, et al. Hepatitis $C$ virus and neurological damage. World J Hepatol. 2016;8(12):545-56. https://doi.org/10.4254/wjh.v8.i12.545

3. Iriana S, Curry MP, Afdhal NH. Neurologic manifestations of hepatitis C virus infection. Clin Liver Dis. 2017 Aug;21(3):535-42. https://doi. org/10.1016/j.cld.2017.03.008

4. Yarlott L, Heald E, Forton D. Hepatitis C virus infection, and neurological and psychiatric disorders - A review. J Adv Res. 2017 Mar;8(2):139-48. https://doi.org/10.1016/j.jare.2016.09.005

5. Di Filippo M, Portaccio E, Mancini A, Calabresi P. Multiple sclerosis and cognition: synaptic failure and network dysfunction. Nat Rev Neurosci. 2018 Oct;19(10):599-609. https://doi.org/10.1038/s41583018-0053-9

6. Heppner FL, Ransohoff RM, Becher B. Immune attack: the role of inflammation in Alzheimer disease. Nat Rev Neurosci. 2015 Jun;16(6):358-72. https://doi.org/1010.1038/nrn3880
7. Saferding V, Blüml S. Innate immunity as the trigger of systemic autoimmune diseases.J Autoimmun. 2020 Jun;110:102382. https://doi. org/10.1016/j.jaut.2019.102382

8. Machado MO, Oriolo G, Bortolato B, Köhler CA, Maes M, Solmi M, et al. Biological mechanisms of depression following treatment with interferon for chronic hepatitis C: a critical systematic review. J Affect Disord. 2017 Feb;209:235-45. https://doi.org/10.1016/j.jad.2016.11.039

9. Belvederi Murri M, Cecere AC, Masotti M, Sammito G, la Marca A, Torres GV, et al. Biopsychosocial predictors of interferon-related depression in patients with hepatitis C. Asian J Psychiatr. 2017;26:24-8. https://doi. org/10.1016/j.ajp.2017.01.001

10. Gascon MRP, Benute GRG, Macedo EC, Capitão CG, Bermudez JEV, Smid J, et al. Cognitive assessment in patients with Hepatitis C submitted to treatment with Sofosbuvir and Simeprevir or Daclatasvir. Arq Neuro-Psiquiatr. Arq Neuropsiquiatr. 2020;78(6):342-348. https://doi.org/10.1590/0004-282X20200022

11. Schwartz CE, Michael W, Zhang J, Rapkin BD, Sprangers MAG. Assessing reserve-building pursuits and person characteristics: psychometric validation of the reserve-building measure. Qual Life Res. 2018 Feb;27(2):423-36. https://doi.org/10.1007/s11136-017-1694-2 